\title{
Optical characterization of Diesel and water emulsion fuel injection sprays using shadowgraphy
}

\author{
D.R. Emberson ${ }^{\mathrm{a}, *}$, B. Ihracska ${ }^{\mathrm{b}}$, S. $\operatorname{Imran}^{\mathrm{c}}$, A. Diez ${ }^{\mathrm{d}}$ \\ ${ }^{a}$ Norwegian University of Science and Technology, NTNU, NO-7491 Trondheim, Norway \\ ${ }^{\mathrm{b}}$ School of Engineering, University of Hertfordshire, AL10 9AB, UK \\ c Department of Mechanical Engineering, University of Engineering and Technology (City Campus), Lahore, Pakistan \\ d Izmir Institute of Technology, Urla, Izmir 35430, Turkey
}

\section{H I G H L I G H T S}

- Fuel injection sprays have been examined using a focused shadowgraph system.

- Diesel and Diesel and water emulsions containing $10 \%$ and $20 \%$ water examined.

- Temporal evolution of the spray cone angle and tip penetration have been measured.

- Emulsification reduced the cone angle at injection pressure of 500 bar.

- Emulsification had no discernable influence on the tip penetration.

\section{A R T I C L E I N F O}

\section{Article history:}

Received 8 October 2015

Received in revised form 4 January 2016

Accepted 5 January 2016

Available online 12 January 2016

\section{Keywords:}

Diesel water emulsions

Fuel injection sprays

Shadowgraph

Cone angle

\begin{abstract}
A B S T R A C T
Diesel fuel and water emulsions have been shown to reduce emissions of $\mathrm{NO}_{x}$ and $\mathrm{PM}$ from compression ignition engines. There is a lack of work examining the influence of emulsification on the sprays formed during injection. This work examines the spray cone angle and tip penetration of Diesel fuel and water emulsions, containing $10 \%$ and $20 \%$ water (by mass). All experiments were conducted under nonreacting, non-vaporizing conditions in a constant volume pressure chamber filled with nitrogen. A focused shadowgraph system, with high speed photography, coupled with a research, high current LED system was used. Differences in the spray cone angle suggest the emulsification did have an effect for the injections at a pressure of 500 bar. Emulsification had no discernible effect on the spray tip penetration. Spray tip penetration showed agreement with previous trends in terms of proportionality to time after start of injection however agreement with models found in the literature was not consistent.
\end{abstract}

() 2016 Elsevier Ltd. All rights reserved.

\section{Introduction}

The use of the internal combustion engine is accompanied by the emission of a range of combustion products into the atmosphere. The legislation of these emissions has become more stringent in previous years as the understanding and concern about environmental pollution has drastically increased [1]. Of particular concern are the emissions of soot, particulate matter (PM) and nitrogen oxides $\left(\mathrm{NO}_{x}\right)$ [2]. This paper focuses on a Diesel fuel additive in the form of water to create Diesel fuel and water emulsions (Diesel fuel emulsions from here). Such emulsions have shown the potential to assist in the control of these emissions from a compression ignition $(\mathrm{CI})$ engine [3].

\footnotetext{
* Corresponding author. Tel.: +47 73593978.

E-mail address: david.r.emberson@ntnu.no (D.R. Emberson).
}

\subsection{Emulsions}

A Diesel fuel emulsion is a mixture of the base fuel (Diesel), defined as the oil or continues phase, with water, the dispersed phase. Water is added to the Diesel fuel in the range of $10-30 \%$ by mass or volume. A small amount of surfactant, usually in the range $1-5 \%$ is used to stabilize the emulsion. A surfactant is a substance that is adsorbed at the interface of the system and alters the inter-facial free energy of the interface. The Diesel fuel emulsion is then utilized in the $\mathrm{CI}$ engine as normal. The use of Diesel fuel emulsions has been shown to reduce $\mathrm{NO}_{x}, \mathrm{CO}$, soot, hydrocarbons (HC) and PM emissions when used in a $\mathrm{CI}$ engine [3-10]. Diesel fuel emulsions have also been shown to slightly improve the brake thermal efficiency of a $\mathrm{CI}$ engine [8,10-12].

There has been very little work done investigating the spray characteristics of Diesel fuel emulsions, which contributes to a 


$\begin{array}{ll}\text { Nomenclature } \\ A & \text { triangle area } \\ C & \text { empirical constant } \\ \rho_{f} & \text { fuel density } \\ \rho_{a} & \text { ambient density } \\ \mathrm{CO} & \text { carbon monoxide } \\ \mathrm{HC} & \text { hydrocarbon } \\ \mathrm{NO}_{x} & \text { nitrogen oxides } \\ P & \text { pressure } \\ \mathrm{PM} & \text { particulate matter } \\ S & \text { spray tip penetration } \\ t & \text { time } \\ \theta & \text { spray cone angle }\end{array}$

\section{Abbreviations}

$\mathrm{CI} \quad$ compression ignition

DAQ data acquisition

EOI end of injection

HLB hydrophilic-lipophilic balance

ICE internal combustion engine

SOI start of injection

TTL transistor transistor logic general lack of understanding concerning their use in direct injection $\mathrm{CI}$ engines. This study goes some way to address this through the optical characterization of Diesel fuel emulsion sprays. The primary break-up of the spray has been considered with secondary break-up not considered. For this aim the spray parameters used to characterize the sprays is the spray cone angle and the spray tip penetration.

\subsection{Characterization of fuel sprays}

The primary break-up of fuel injection sprays is difficult to characterize using conventional optical measurement techniques (such as the phase Doppler technique or PIV) due to the density of the spray in that region. Hence spray cone angle and tip penetration, which can be obtained using photographic techniques, are among the most frequently reported parameters in fuel-spray research [13]. Schlieren and shadowgraphy are two related techniques used to visualize the spatial variation of density in a transparent medium, which in most cases is a gas (e.g. air). Both techniques have previously been utilized, in various forms, to examine and characterize fuel injection spray parameters [14-18].

Previous experimentation has found that the spray cone angle depends on the density of the ambient atmosphere into which the spray emanates, with models based upon experimental work commonly taking the form [19-21]

$\theta=\propto\left(\frac{\rho_{a}}{\rho_{f}}\right)^{a}$

where $\rho_{a}$ is the ambient density, $\rho_{f}$ is the fuel density and $a$ is an experimentally derived constant. Such models show $\theta$ to be a function of the ratio of liquid and gas densities $\left(\rho_{a} / \rho_{f}\right)$, not the injection velocity (hence injection pressure). The work [21] includes a review of the relationship between spray cone angle and the density ratio as well as experimental findings and reports $a=0.19$, with no significant influence from the injection pressure.

In much of the previous work, the temporal development of the spray cone is ignored [16], with experimental fits to proposed models taken from the quasi-steady/constant period of spray cone angle. Table 1 shows some spray cone angles (from the period of constant value) and the time after SOI when the angle is observed to become constant (transition time) that have been presented in previous works. Considering that the time involved for the spray to reach its quasi-steady angle is of the same order as a typical ignition delay period in a $\mathrm{Cl}$ engine, any influence on mixing may be overlooked.

The temporal development of the spray tip penetration into the combustion chamber has been examined for a number of years. The most widely excepted findings and developed correlations come from the work of Hiroyasu and Arai [20] which is still used for comparison purposes in current work [16,28,29]. In [20], two distinct periods of tip development were identified. An early stage of the spray development where $S \propto t$ followed by a transition to a period where $S \propto t^{1 / 2}$. The spray velocity during the early period is modeled as constant and spray develops as a steady jet. The time when the transition occurs is described as the breakup time which was shown to decrease with increasing injection pressure. The Hiroyasu and Arai model is often presented in the form

$0<t<t_{\text {break }} \quad S(t)=0.39 \sqrt{\frac{2 \Delta P}{\rho_{f}} t}$
$t \geqslant t_{\text {break }} \quad S(t)=2.95\left(\frac{\Delta P}{\rho_{a}}\right)^{\frac{1}{4}} \sqrt{d_{0} t}$

where, $\quad t_{\text {break }}=\frac{29 \rho_{f} d_{n}}{\left(\rho_{g} \Delta P\right)^{\frac{1}{2}}}$

The reason behind the discontinuity between the two periods has not always been accepted, though the linear relationship during the early period has been accepted for many years. Hiroyasu and Arai [20] describe the spray as not fully atomized resulting in a penetration with a constant velocity, hence the transition time is the time where breakup occurs. Nabers and Siebers [21] described the transition time as the time where the spray is dominated by injected liquid being dominated by entrained gas.

The linearity of the initial stage has come into question in some recent studies [15]. The instant the injector opens, the spray jet velocity must be zero, an infinitesimal period of time later a sharp rise in spray jet velocity must occur (acceleration) hence the linearity of the initial period does not make physical sense [29]. With this in mind, the work [29] developed an empirical model from an experimental campaign conducted at a much higher temporal resolution than most other work and specifically investigated the early period of spray evolution. The model is in the form

Table 1

Spray cone angles and transition times observed in previous studies.

\begin{tabular}{lll}
\hline Previous study & $\theta^{\circ}$ & Transition time $(\mu \mathrm{s})$ \\
\hline$[15]$ & 30 & 1000 \\
{$[16]$} & 20 & 400 \\
{$[21]$} & 20 & 500 \\
{$[22]$} & $15-20$ & 600 \\
{$[23]$} & 20 & 300 \\
{$[24]$} & 15 & $1000-1200$ \\
{$[25]$} & $10-18$ & 150 \\
{$[26,27]$} & - & 300 \\
\hline
\end{tabular}


$S(t)=C t^{3 / 2}$

where $C$ is an empirically fitted constant and no physical explanation is attempted to derive or explain the relationship. Upon differentiating, the spray tip velocity, $U$, is proportional to $t^{0.5}$, which is not ill defined as $t$ approaches zero [29]. The Kostas findings appear to be more physically realistic but also show poor agreement with the Hiroyasu model.

The work [16] builds upon the findings presented in [29]. An empirical relationship of injection parameters and the initial period to determine the values of $A$ are presented in the form

$S(t)=\left(\frac{\rho_{f}}{\rho_{g}}\right)^{0.25}\left(\frac{\rho_{g}^{1 / 3} \Delta P}{12 \rho_{f}}\right)^{0.5} t^{3 / 2}$

In the work [29] the penetration after the $t_{\text {break }}$ is considered to be the same as in the Hiroyasu model while [16] introduced a nozzle conicity term to take into account any cavitation effects in the form

$S(t)=2.95\left(\frac{\Delta P}{\rho_{a}}\right)^{0.25} \sqrt{\left(C_{f}\right)^{z} d_{o} t}$ fort $\geqslant t_{\text {break }}, \quad C_{f}=\frac{d_{i}}{d_{o}}$

where $d_{i}$ is the inlet diameter and $d_{o}$ is the outlet diameter of the nozzle.

Whilst engine testing of emulsified fuels is widely published, fundamental spray experiments are rare. The work [30] is partially concerned with the spray parameters of Diesel fuel emulsions. An emulsion containing $10 \%$ water is injected into a constant volume combustion chamber, under reactive, vaporizing conditions (air at $830 \mathrm{~K}$ ), with the cone angle measured at 42 and 112 nozzle diameters downstream of the nozzle. The emulsion fuel droplets and ligaments (not tip penetration) were observed to penetrate further than with pure Diesel fuel. The cone angles were observed to be very similar for each fuel. No conclusions concerning the fundamental nature of the spray parameters were made.

The works [31,32] were conducted in a constant volume, precombustion chamber at 800 and $1200 \mathrm{~K}$ under reactive conditions. The emulsions examined were $10 \%$ and $20 \%$ water produced in a homogenizer, injection pressure was $70 \mathrm{MPa}$. A longer tip penetration for the emulsions and a thickened spray at the beginning of the injection period was observed. This is stated to be due to the higher viscosity and surface tension of the emulsions. At the $1200 \mathrm{~K}$ temperature, the tip penetrations for the Diesel and the emulsions were similar.

\section{Experimental set-up}

\subsection{High pressure chamber design}

All tests were conducted in a stainless steel high pressure chamber with optical access. The chamber was charged with nitrogen at the ambient temperature of $20^{\circ} \mathrm{C}$. Two chamber pressures were considered, 20 and $30 \mathrm{bar}$, corresponding to two ambient gas densities of $22.6 \mathrm{~kg} / \mathrm{m}^{3}$ and $34.5 \mathrm{~kg} / \mathrm{m}^{3}$ respectively. Maximum observable length of spray was in the region of $60 \mathrm{~mm}$. Window fouling was avoided using a solenoid valve that opened for a short duration after an injection, purging the chamber of the injected fuel. It took approximately 2 min after purging for the chamber to return to the corresponding pressure and temperature. Fuel injection was by means of a research, high pressure common rail system. The injector was an asymmetric, seven hole, piezo actuated Siemens mini-sac type. Due to the arrangement of the nozzle holes, it was necessary to block all but one hole to allow single spray examination. The holes were blocked by laser welding using a jewelers welding rig. The common rail pressure was measured by a pressure transducer fitted in the rail and was taken to be the injection pressure. The high pressure pump was a double ended hydraulic type (Sprague P4333), driven by compressed air capable of supplying fuel to the rail at up to $200 \mathrm{MPa}$. The outlet pressure was controlled via the compressed air inlet pressure, once this was set at the regulator, no adjustment or control was required to maintain the outlet pressure. The injector was controlled by a Hartridge HK853 driver which was triggered from a TTL signal controlled from a custom LabView program.

\subsection{Optical arrangement}

A double pass, single mirror schlieren/shadowgraph system using a high power LED provided the optical diagnostic. The mirror is a spherical, concave $101 \mathrm{~mm}$ diameter with focal length of $1219 \mathrm{~mm}, f / 12$, mounted into a positioning mechanism. The mirror was placed as close as possible to the back window of the chamber. The point light source was placed a distance of two focal lengths from the center of the mirror. The light source is discussed in detail in Section 2.3.

The light returning from the mirror was diverted into the camera lens by a $50 / 50$ beamsplitter which was mounted at a distance of $2133 \mathrm{~mm}$ from the mirror. The Phantom v7.11 camera was positioned with a $200 \mathrm{~mm}$ lens (aperture set to $\mathrm{f} / 11$ ) at a distance of approximately $51 \mathrm{~mm}$ from this focal point. The camera was operated with a resolution of $256 \times 256$ pixels, with an camera exposure time of $33.25 \mu \mathrm{s}$. Maximum frame rate at this resolution was 30,075 frames per second. A schematic of the system is shown in Fig. 1. The camera was triggered by the same TTL which triggered the injector driver, whilst the image sequences were recorded on a dedicated camera computer.

\subsection{L.E.D illumination system}

In order to achieve suitable images at the frame rate desired, a high intensity, short duration light source was required. At $30,075 \mathrm{fps}$, maximum exposure time is approximately $30 \mu \mathrm{s}$. This length of exposure is too long to "freeze" the spray to produce images with well defined, sharp edges and tips. Exposure times in the region of $1-10 \mu$ s were found to be ideal for this purpose.

A pulsed, overdriven current LED system based upon the work in [33-38] was developed for use in this study. The system consisted of a high power, green Phatlight CBT-40 LED [39] which is rated to operate with a current of $5.9 \mathrm{~A}$ continuous or $9.8 \mathrm{~A}$ pulsed ( $50 \%$ duty cycle). The LED was controlled by a circuit consisting of a bank of capacitors which were charged by the supply voltage, $30 \mathrm{~V}$ in this study. The capacitors discharge through the LED, switched by a MOSFET power transistor with TTL compatible input. Current through the LED was determined by measuring the voltage across a resistor on the MOSFET ground side with an oscilloscope. The LED pulse was controlled by the TTL input to the MOSFET, which is generated by a LabView program running on the DAQ PC. The LED period was set at $33.25 \mu \mathrm{s}$, to match the cameras frame rate. The pulse width (time when LED is on) was set to $3 \mu \mathrm{s}$, hence the effective exposure time was $3 \mu \mathrm{s}$.

With these settings, the current through the LED was approximately $60 \mathrm{~A}$. In the work [37] this same LED was shown to increase in light emission with increasing drive current with a proportionality of approximately 0.35 beyond currents of $10 \mathrm{~A}$. Using the 0.35 proportionality, the increase in current from $9.8 \mathrm{~A}$ to the $60 \mathrm{~A}$ used in this study will result in an effective pulse power of $21 \mathrm{~W}$. Fine tuning of camera and LED syncing was possible by inducing a small delay in the camera from the trigger to account for any discrepancies between the LabView clock and the camera clock and any lag induced in the system. The LED system performed extremely well, was low cost and avoided many of the health and safety issues that are imposed when using lasers. 


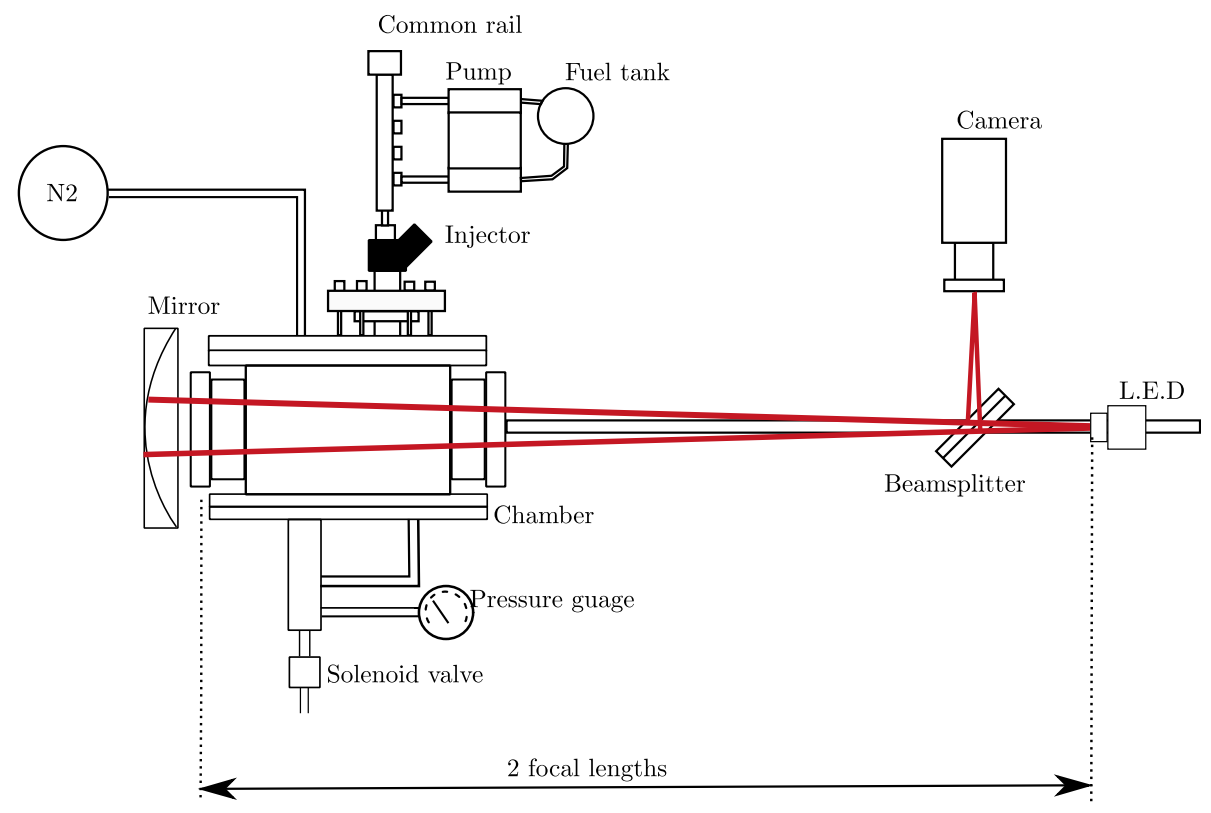

Fig. 1. Schematic of the focused shadowgraph system used with the high pressure chamber.

\subsubsection{Emulsion production}

The Diesel fuel emulsions were made using standard pump Diesel fuel with the addition of $10 \%$ and $20 \%$ of water (by mass). The choice of suitable surfactant was made using the hydrophilic-lipophilic balance (HLB) methodology and results of previous studies $[5,11,31,40,41]$. The two surfactants used were Span 80 , a nonionic lipophilic surfactant with a HLB of 4.3 and Tween 80 , a non-ionic hydrophilic surfactant with a HLB of 15 . It was found that the surfactant mix resulting in a HLB of approximately 6.4 (80\% Span 80 and $20 \%$ Tween 80 ) resulted in the most stable emulsion [42]. It has been seen in studies elsewhere [40,43] that the use of mixture of Span 80 and Tween 80 leads to better results compared with the use of a single surfactant with equivalent value of HLB. The emulsion was produced by ultrasonic mixing using an ultrasound generator (Sonics, Vibra-cell $750 \mathrm{~W}, 20 \mathrm{kHz}$ ) and a ultrasonic probe (Model CV33). The ultrasonic method of mixing has been used elsewhere $[4,44-46]$ and has been shown to result in: smaller mean droplet size; larger number of water droplets that are distributed more uniformly in the continuous phase; lower separating rates of the water droplets from the emulsions when compared with emulsions prepared by a more conventional mechanical homogenizer [4]. Ultrasonic emulsification is therefore recognized as a fast, efficient technique for producing tiny and uniformly-sized droplets.

\subsection{Fuel densities and viscosity}

The density and viscosity for each fuel has also been determined and are presented in Table 2. For all cases the viscosity was observed to reach a constant when the shear rate was between 400 and $1000 \mathrm{~s}^{-1}$. The mean value presented is the determined

Table 2

Fuel density and viscosity.

\begin{tabular}{lll}
\hline Fuel & Density $\left(\mathrm{kg} / \mathrm{m}^{3}\right)$ & Viscosity (Pa s) \\
\hline Diesel & 814 & 0.00588 \\
Diesel 10/\% water & 829 & 0.00669 \\
Diesel 20/\% water & 876 & 0.00678 \\
\hline
\end{tabular}

from taking the mean value of this constant period. The measurement was repeated three times and these 3 mean values were used to obtain a mean viscosity of the fuels, stated in Pascal seconds.

\subsubsection{Image processing}

All images were processed using a piece of Matlab script produced by the authors. The image processing is discussed in detail in [47]. The image analysis makes use of the Otsu method to determine global threshold levels (Matlab graythresh) and is independent of any user defined inputs. No image adjustments where made, with the original pixel values and image histogram used for the analysis. The spray tip was defined as the last spray signal along the spray central axis downstream from the nozzle. Spray cone angle was determined using the triangle technique introduced in the work [21] and also utilized in [25,48,49]. The angle corresponds to that of a triangle whose area is equal to the projected area of the upstream half of the spray. The angle $\theta$ is given by

$\theta=2 \tan ^{-1}\left(\frac{A}{(S / 2)^{2}}\right)$

where $A$ is the projected area of the upstream half of the spray, $S / 2$ is half of the tip penetration.

\section{Results and discussion}

\subsection{Spray cone angle}

Fig. 2 shows an example image of a fuel spray collected using the shadowgraph system complete with the image processing stages used to determine the spray cone angle, $\theta_{S}$ and the tip penetration, $S_{S}$ (subscript s for shadowgraph). In Fig. 2 a Diesel spray is shown as it is approaching it's quasi-steady, quasi-constant $\theta_{S}$ period, $1064 \mu$ s after SOI. Sequences of images collected like that shown in Fig. 2 were used to determine the temporal evolution of the spray angle and tip penetration for each fuel tested.

Figs. 3 and 4 show the temporal evolution of $\theta_{S}$ for Diesel fuel, D10 and D20 at the two ambient densities into which the injection took place; $22.6 \mathrm{~kg} / \mathrm{m}^{3} \quad\left(P_{a m b}=20 \mathrm{bar}\right)$ and $34.5 \mathrm{~kg} / \mathrm{m}^{3}$ 

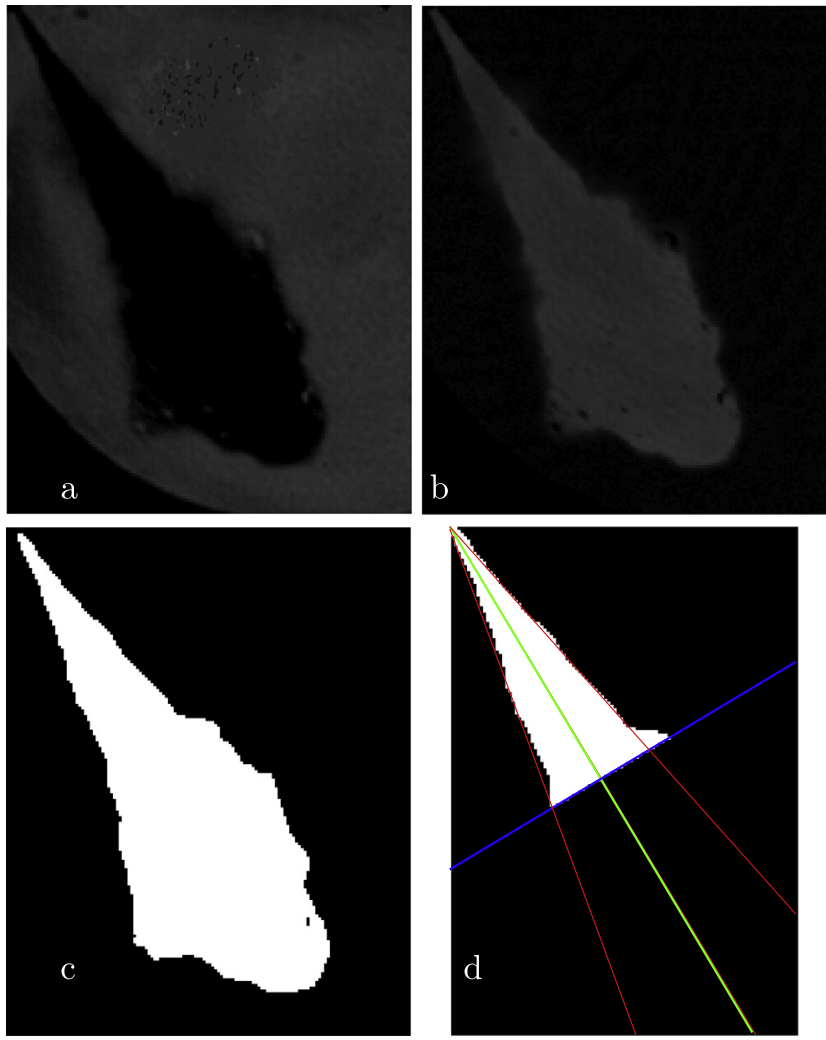

Fig. 2. Shadowgraph Diesel spray image at $t=1064 \mu$ s (thirty third frame containing spray). (a) Raw image, (b) complement image, (c) black and white image, (d) cropped, processed measurement image.

$\left(P_{a m b}=30\right.$ bar $)$. Both figures include error bars the size of one standard deviation $(\sigma)$ from the mean. The interval between each time step was $33.25 \mu$ s (camera frame rate). The plots have been constructed with the injection delay period removed. The end of injection (EOI) was not well defined so a cut-off at frame 55 $(t=1829 \mu$ s after SOI) was used for all cases.

The injections started with a $\theta_{S}$ between $36^{\circ}$ and $52^{\circ}$. As the injection continues, $\theta_{S}$ decreases and appears to approach (quasi) constant values of between $18^{\circ}$ and $24^{\circ}$, after approximately $1000 \mu$ s. The standard deviation associated with the 15 injections used to determine the mean value decreases as the injection progresses, as evidenced by the reduction in the size of the error bars for each condition. This is also an indication that the spray angle value is reaching a quasi-steady, less transient value and the spray is forming a less transient spray structure. Measurement uncertainties were considered and have been determined to arise from the image collection system. Sources of the uncertainty include varying intensity of the LED, window fouling, optical misalignment, lens fouling and camera response. Whilst the magnitude of these uncertainties may not be determined, the measurement uncertainty has been handled by the standard deviation of each data set, evidence by error bars in Figs. 3 and 4 .

Figs. 3 and 4 show that varying the injection pressure had little effect on $\theta_{S}$ for the Diesel fuel sprays. This is in accordance with previous works [20-22,50-52] which found the spray angle for complete atomized sprays to be independent of injection pressure and only dependent on the gas density. For D10 and D20 sprays at $P_{i n j}=500 \mathrm{bar}$, there was a distinct reduction in $\theta_{S}$ compared to their sprays at $P_{i n j}=700$ and 1000 bar. The difference between the D10, D20 and the neat Diesel fuel spray angle at $P_{i n j}=500$ bar are not so pronounced at the higher ambient density. This is evidenced by the larger standard deviation of the angles at the higher density, with
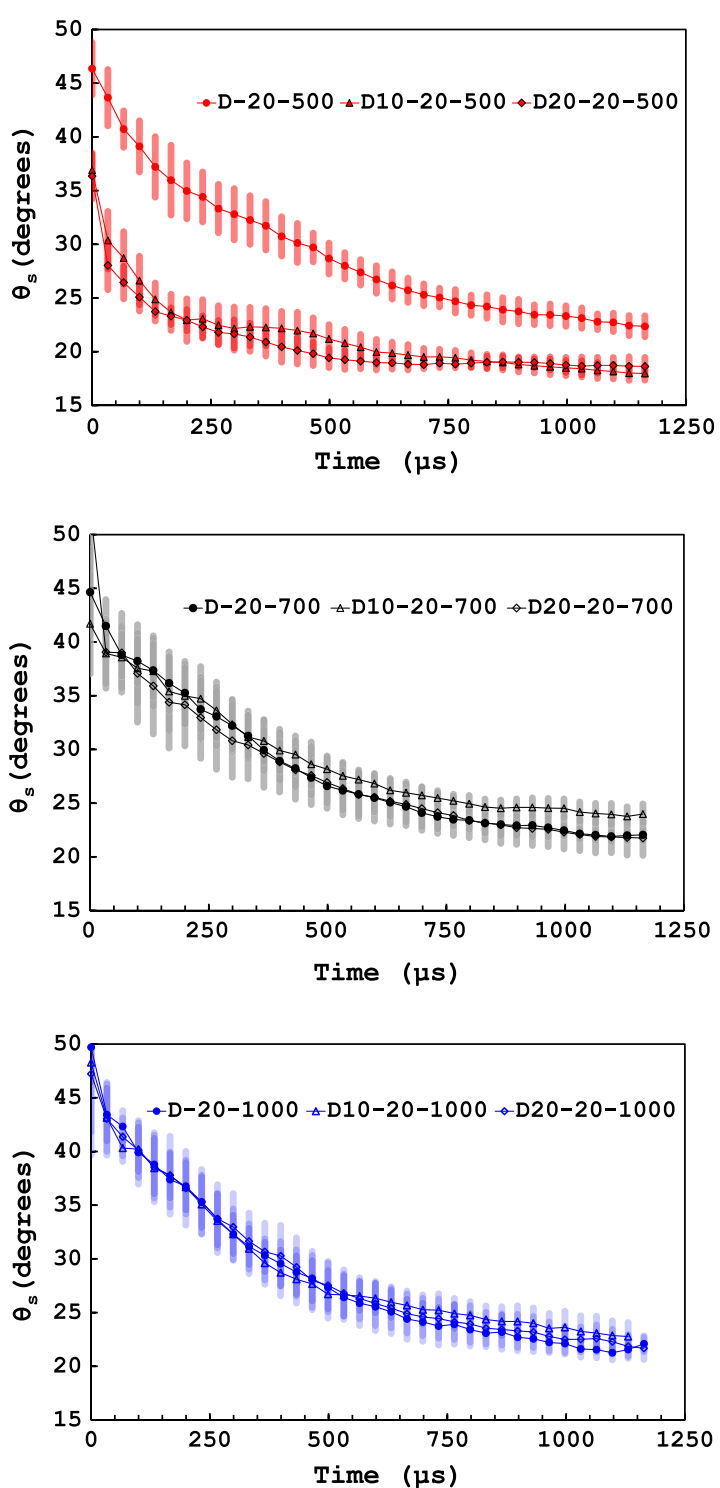

Fig. 3. Fuel injection spray angle variation with time with Diesel fuel (circle), D10 (triangle) and D20 (diamond) and ambient gas density $\rho_{a}=22.6 \mathrm{~kg} / \mathrm{m}^{3}$ $P_{a m b}=20$ bar. 500 bar are shown in red, 700 bar in black and 1000 bar in blue line. Error bars are the size of one standard deviation for the 15 injections used to calculate the mean. (For interpretation of the references to color in this figure legend, the reader is referred to the web version of this article.)

considerable overlap of the error bars. It is evident that the emulsification process had an impact on the fuel spray angle at the injection pressure of 500 bar. The difference in $\theta_{S}$ between the two emulsions was small at this injection pressure. The emulsification process appears to have reduced $\theta_{S}$ when compared with the neat Diesel sprays (at $P_{i n j}=500$ bar) by between $3^{\circ}$ and $4.5^{\circ}$ approximately.

Figs. 3 and 4 show that for all injection pressures, an increase in $\rho_{a}$ lead to an increase in the $\theta_{S}$ for the neat Diesel fuel sprays but not for the emulsified fuel sprays. This is shown a little more clearly in Fig. 5 which shows the average, quasi-steady spray angle $\left(\theta_{\text {Sav }}\right)$ from the arithmetic mean of the final $5 \theta_{S}$ values (time after SOI $=1097 \mu$ s to $1230 \mu$ s) for each condition. This value is used as a representative value of the spray cone angle for each condition. In Fig. 5 the measured $\theta_{\text {sav }}$ for the neat Diesel fuel are of a similar value for each injection pressure at the same ambient density. As the ambient density was increased, $\theta_{\text {Sav }}$ shown a small increase. For the D10, the $\theta_{\text {Sav }}$ of the 500 bar injection at each ambient 

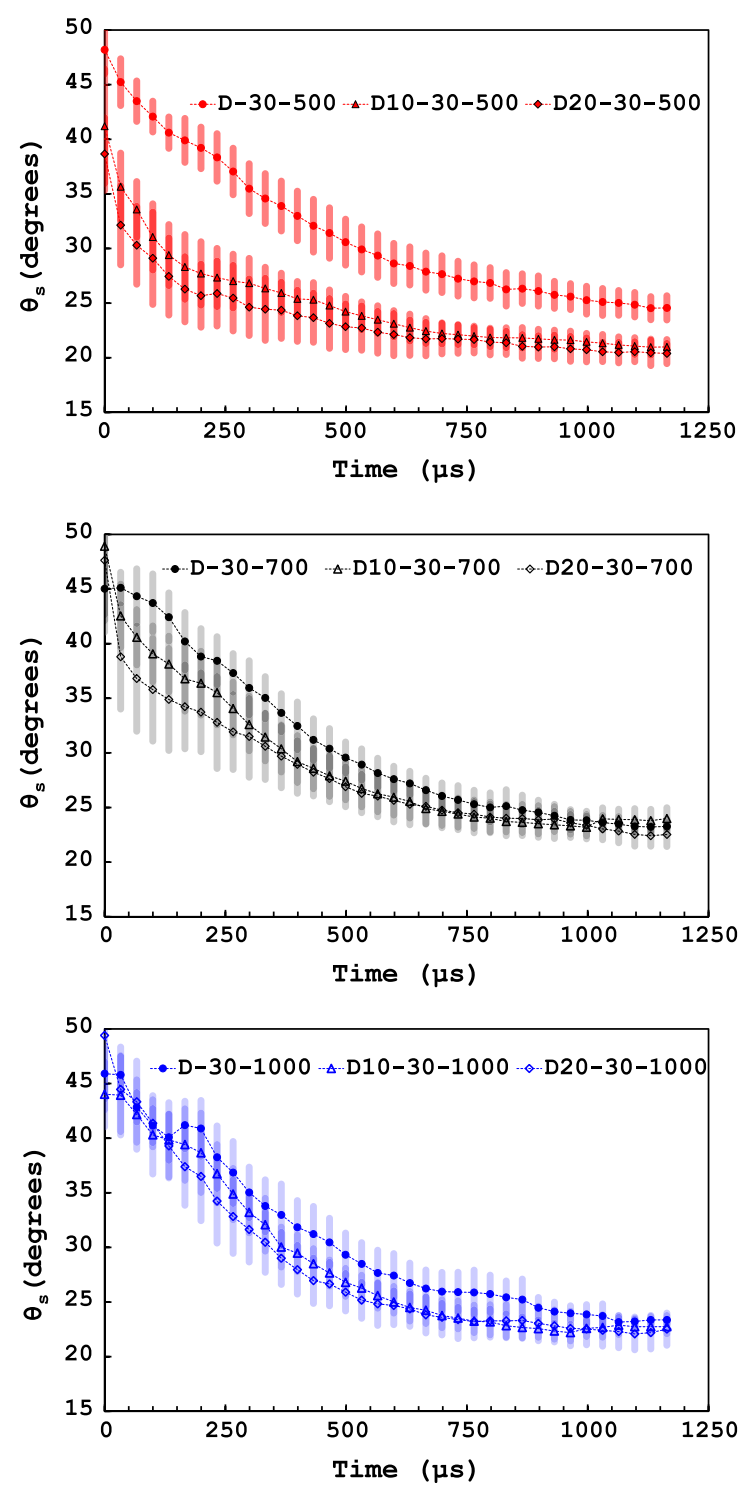

Fig. 4. Fuel injection spray angle variation with time with Diesel fuel (circle), D10 (triangle) and D20 (diamond) and ambient gas density $\rho_{a}=34.5 \mathrm{~kg} / \mathrm{m}^{3}$ $P_{a m b}=30$ bar. 500 bar are shown in red, 700 bar in black and 1000 bar in blue line. Error bars are the size of one standard deviation for the 15 injections used to calculate the mean. (For interpretation of the references to color in this figure legend, the reader is referred to the web version of this article.)

density was much lower than for the 700 and 1000 bar injections. The small increase in the $\theta_{\text {sav }}$ with the increase in ambient density was not observed for the 700 and 1000 bar injections. This trend is repeated for the D20 fuel sprays.

The spray angle is known to be a function of the ratio of the ambient (gas) density and fuel (liquid) density $\left(\rho_{a} / \rho_{f}\right)$. Compared with previous works, the range of the density ratios in this study was limited, with only two chamber pressures being used, 20 bar and $30 \mathrm{bar}$; resulting in two ambient densities of $22.6 \mathrm{~kg} / \mathrm{m}^{3}$ and $34.5 \mathrm{~kg} / \mathrm{m}^{3}$ respectively. The emulsification process resulted in a change of the fuel density as well. The fuel densities were measured to be $814 \mathrm{~kg} / \mathrm{m}^{3}, 829 \mathrm{~kg} / \mathrm{m}^{3}$ and $876 \mathrm{~kg} / \mathrm{m}^{3}$ for D, D10 and D20 respectively (Table 2 ). The resultant density ratio range is 0.026-0.042, which is lower than that of a modern, turbocharged common rail CI engine. Fig. 6 shows the variation of the average, quasi-steady spray angle $\left(\theta_{\text {Sav }}\right)$ with the density ratio $\rho_{a} / \rho_{f}$ for Diesel fuel, D10 and D20 sprays. For each of the plots

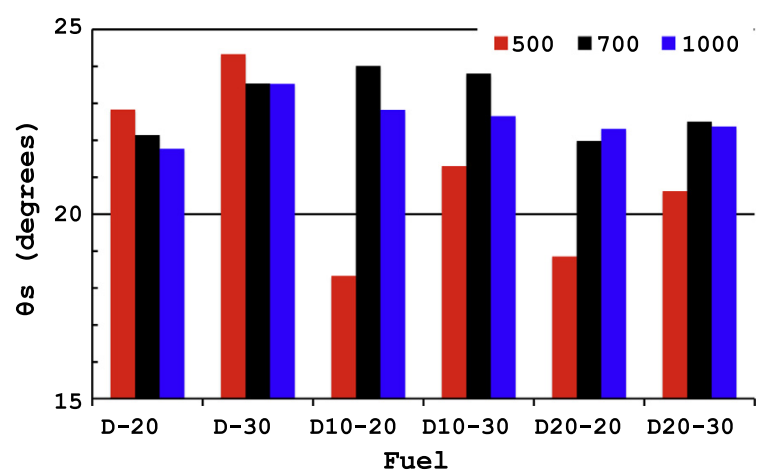

Fig. 5. Representative spray cone angle value taken from the quasi-steady, near constant period at the EOI for Diesel fuel, D10, D20 at each condition. All 500 bar injections are in red, 700 bar in black and 1000 in blue. -20 are injections are with $\rho_{a}=22.6 \mathrm{~kg} / \mathrm{m}^{3} \quad P_{a m b}=20 \mathrm{bar}, \quad-30$ are injections with $\rho_{a}=34.5 \mathrm{~kg} / \mathrm{m}^{3}$ $P_{a m b}=30$ bar. (For interpretation of the references to color in this figure legend, the reader is referred to the web version of this article.)
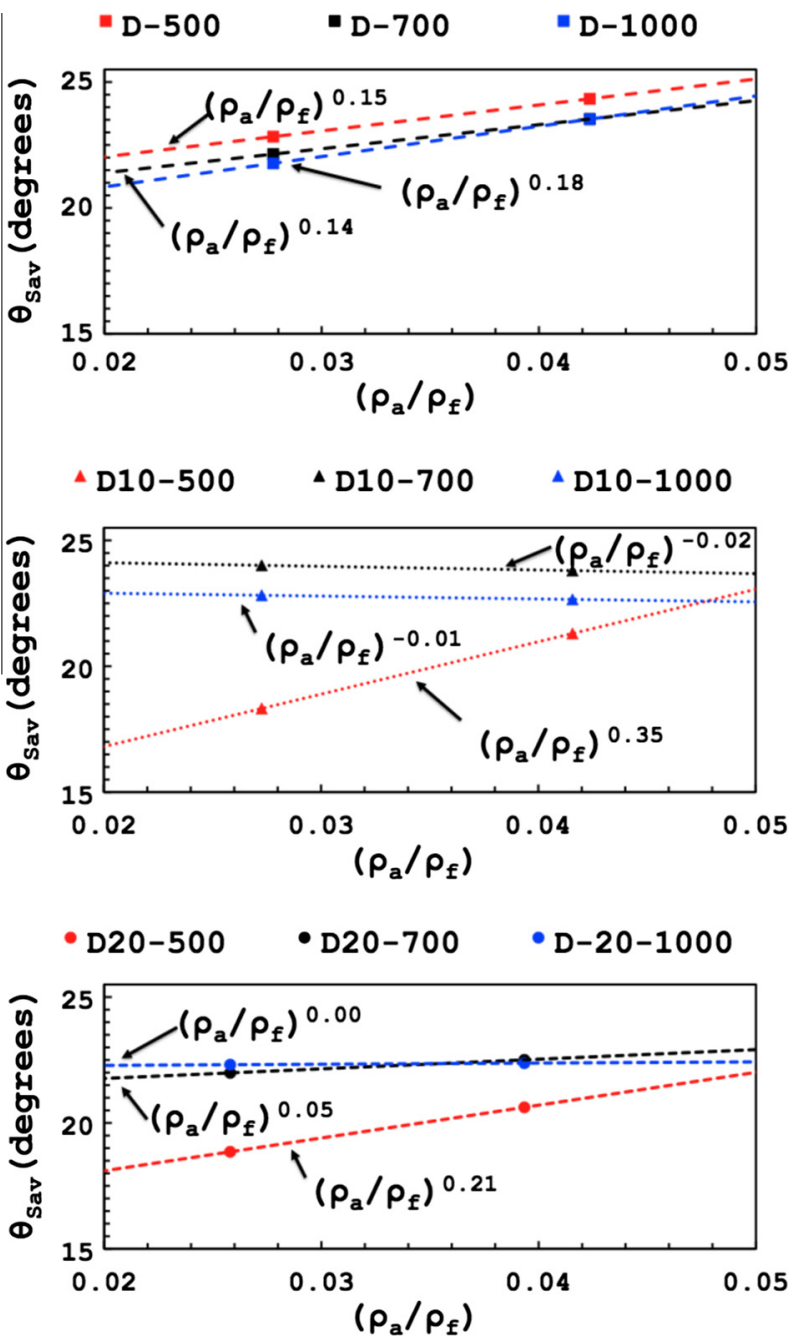

Fig. 6. Variation of the $\theta_{\text {Sav }}$ of Diesel fuel spray with $\rho_{a} / \rho_{f} . P_{i n j}=500$ (red), 700 (black) and 1000 bar (blue). Trend line has been fitted to the points for each injection pressure with the exponent shown. (For interpretation of the references to color in this figure legend, the reader is referred to the web version of this article.)

the red broken line is fitted to the 500 bar injection, the black broken line to the 700 bar injections and the blue broken line to the 1000 bar injections. The exponent of the density ratio ( $a$ where 
$\left.\theta \propto\left(\rho_{a} / \rho_{f}\right)^{a}\right)$ for each injection pressure and fuel was determined using logarithms. For the neat Diesel fuel sprays, each injection pressure shows a similar trend, with the exponent of the density ratio for each pressure very similar, $\left(\rho_{a} / \rho_{f}\right)^{0.14-0.18}$. These values are in accordance with previous findings for Diesel fuel sprays. The injection pressure had little, to no effect and the increase in density ratio resulted in an increase of the spray cone angle. For D10 and D20, the 500 bar injections had a much smaller spray angle at the lower ambient density than for the 700 and 1000 bar injections. The spray angle of the 500 bar injections did increase with the increasing density ratio, with $a=0.35$ and 0.21 for D10 and D20 respectively. The angle for the 500 bar injections for both emulsified fuels was smaller than it's neat Diesel counterpart.

The increase in spray angle with density ratio is not observed for the two emulsified fuels at the injection pressures of 700 and 1000 bar. This is demonstrated by the small value of $a$ for these conditions; -0.02 (700 bar, D10 injections) to 0.05 (700 bar, D20 injections). Fig. 6 supports the statement that the emulsified fuels, at 700 and 1000 bar injection pressure, shown no change in the spray angle with changing ambient density.

The values of $a$ have been determined using two data points. The findings are not being overstated or stated outside of the measurement range of the experimentation conducted here, the limitations of the findings are accepted. The values determined for the neat Diesel fuel are reasonable when compared with previous findings so it is fair to say that the values should also be realistic for the emulsified fuels. The value of $a$ determined is being used as an indicator of any effects the emulsification had at these conditions and not as a fundamental finding of the sprays. The value $a$ for the D10 and D20, 500 bar injections suggests that at $P_{i n j}=500 \mathrm{bar}$, the emulsification results in the ambient density increase having a larger effect on the spray cone angle compared with neat Diesel, but the actual value of the spray angle is reduced relative to the neat Diesel sprays at these conditioned. The emulsification suppressed the effect of the ambient density increase for the 700 bar and 1000 bar injection pressures.

\subsection{Tip penetration}

Figs. 7 and 8 show the temporal evolution of the spray tip penetration for Diesel fuel, D10 and D20 sprays at each injection pres-
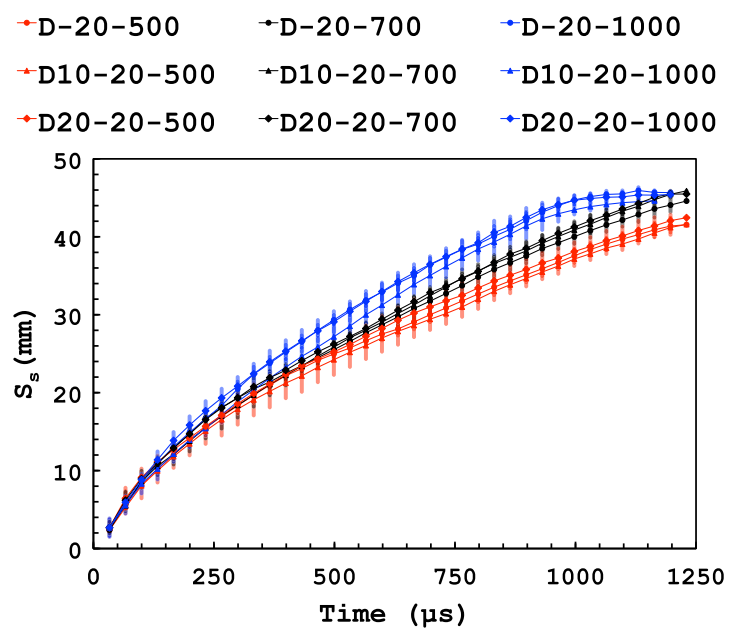

Fig. 7. Fuel injection spray tip penetration variation with time after SOI for Diesel fuel, D10 and D20. $P_{i n j}=500,700$ and 1000 bar. $\rho_{a}=22.6 \mathrm{~kg} / \mathrm{m}^{3}\left(P_{a m b}=20 \mathrm{bar}\right)$ Error bars of one standard deviation. Determined using the shadowgraph image sequences.

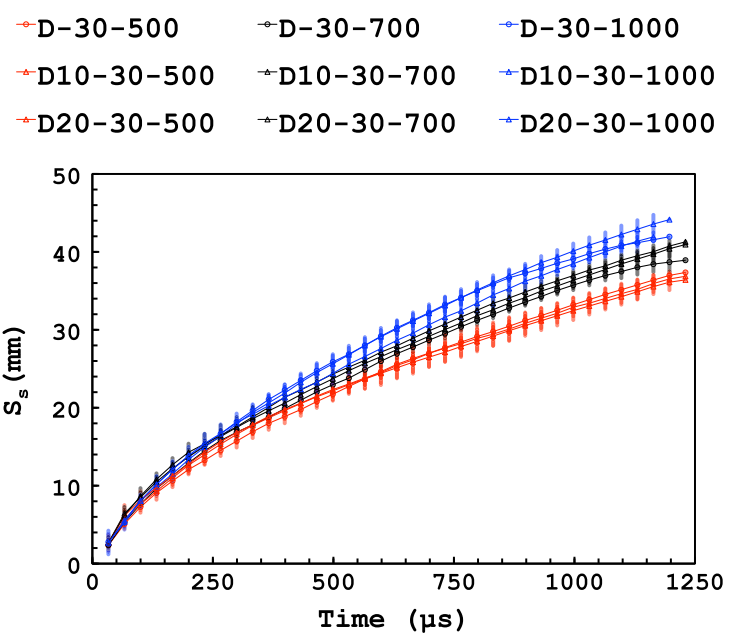

Fig. 8. Fuel injection spray tip penetration variation with time after SOI for Diese fuel, D10 and D20. $P_{i n j}=500,700$ and 1000 bar. $\rho_{a}=34.5 \mathrm{~kg} / \mathrm{m}^{3}\left(P_{a m b}=30 \mathrm{bar}\right)$. Error bars of one standard deviation. Determined using the shadowgraph image sequences.

sure with ambient density of $22.6 \mathrm{~kg} / \mathrm{m}^{3}$ and $34.5 \mathrm{~kg} / \mathrm{m}^{3}$ respectively. The mean value shown is determined from 15 injections. As with the spray cone angle values, the injection delay period has been removed. The first appearance of spray has not been set at $t=0$ as this would lead to a physically impossible situation where the spray started before $t=0$. The tip penetration has not been back extrapolated to $0 \mathrm{~mm}$ at $t=0$ as this relies on the assumption that the initial rate of penetration (velocity) during the very early period of the spray evolution was linear with time. Due to the varying injection delay between each condition and the temporal resolution only being as high as the camera frame rate $(33.25 \mu \mathrm{s})$, a linear correction was applied to align the penetration profiles so all profiles have a common origin. The common origin was set at $t=33.25 \mu$ s with each tip measurement made at $33.25 \mu$ s intervals (frame rate of the camera). The linear correction allows a fair comparison between each case to be made and observe the change in tip penetration for each time step. Both figures include error bars the size of one standard deviation $(\sigma)$ from the mean for the 15 injections used to calculate the mean $S_{s}$. The standard deviation from the mean was included to show the good repeatability between each injection event and the statistical significant of the mean $S_{S}$ determined. Figs. 7 and 8 demonstrate that emulsification seemed to have had little to no effect on the temporal evolution of the spray tip penetration when compared with the neat Diesel spray results.

As has been noted in previous works [17,18,28,29], increasing the injection pressure lead to an increase in rate of the spray tip penetration while an increase in the ambient density lead to a reduction in the rate of the spray tip penetration. An increase in $P_{i n j}$ results in an increase in the spray momentum and an increase in $\rho_{a m b}$ results in an increase in aerodynamic drag on the emerging spray.

An example of the methodology of the tip penetration analysis influenced by the Hiroyasu and Arai model is to examine the temporal tip penetration using a log plot. Experimental data points are plotted on a logarithmic plot as in Figs. 9 and 10 and were used to create average trend lines.

As described by Hiroyasu and Arai [20] and in subsequent works $[13,17,21,53]$ the plots describe two distinct periods of spray tip temporal evolution. The slope of the initial period of the curve is usually described as being equal to 1 . The slope of the initial period of the curve in Figs. 9 and 10 is 1.12 and 1.03 respectively which is in reasonable agreement. During this period the rate of spray tip 


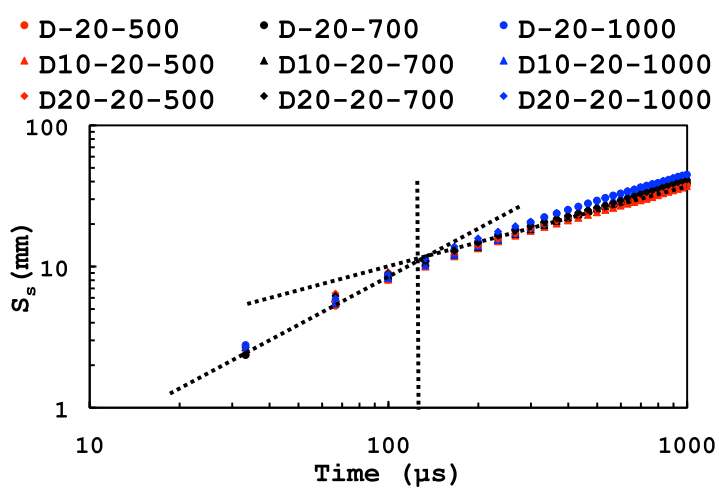

Fig. 9. Log-penetration with log-time plot for Diesel fuel, D10 and D20 spray tip penetration. $P_{i n j}=500,700$ and 1000 bar. $\rho_{a}=22.6 \mathrm{~kg} / \mathrm{m}^{3}\left(P_{a m b}=20 \mathrm{bar}\right)$. Determined using the shadowgraph image sequences. Linear trend line fitted to the two portions of the tip penetration with intersection at break-up time.

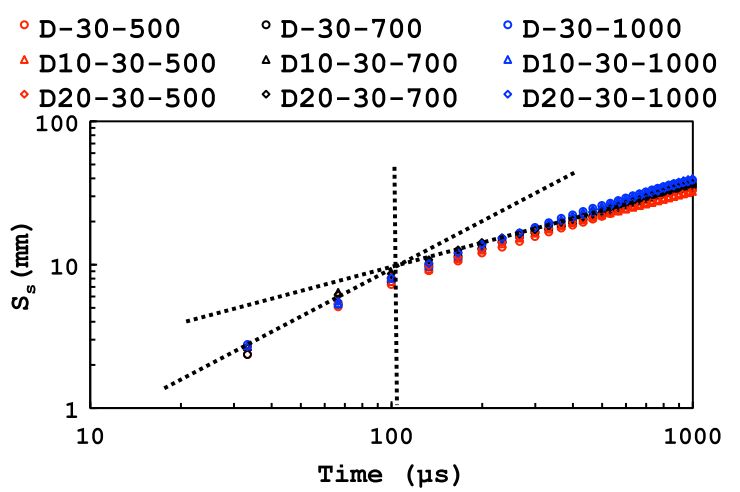

Fig. 10. Log-penetration with log-time plot for Diesel fuel, D10 and D20 spray tip penetration. $P_{i n j}=500,700$ and 1000 bar. $\rho_{a}=34.5 \mathrm{~kg} / \mathrm{m}^{3}\left(P_{a m b}=30 \mathrm{bar}\right)$. Determined using the shadowgraph image sequences. Linear trend line fitted to the two portions of the tip penetration with intersection at break-up time.

penetration was nearly linear with time, $S \propto t$, and is thought to be dominated by the propagation of the liquid core into the surrounding atmosphere [25]. The tip velocity is thought to be determined by the fuel injection velocity because the momentum exchanged between the spray and the surrounding ambient atmosphere is not significant during the very early period [15].

After a short time the slope changes and is most often approximated to a value of $0.5\left(S \propto t^{0.5}\right)$. The slope of the curve in this second period in Figs. 9 and 10 is 0.6. This transition is often described as the spray break-up time and is defined as the time where the fuel spray starts to exchange momentum with the surrounding atmosphere and the tip velocity is reduced, this may be referred to as aerodynamic drag in some cases. It is also suggested this transition time is the instance when spray mixture changes from being dominated by injected liquid to being dominated by entrained gas $[21,53]$. The vertical broken line in Figs. 9 and 10 shows the average transition time for the $\rho_{a}=22.6$ and $\mathrm{kg} / \mathrm{m}^{3} \rho_{a}=34.5 \mathrm{~kg} / \mathrm{m}^{3}$ conditions. The times have been extracted and are shown in Table 3. As the ambient density is increased the transition time after the SOI becomes shorter. The increase in the ambient density has lead to a reduction in the break-up time due to increasing aerodynamic drag and momentum exchange with the ambient gas.

Table 3

Spray tip penetration transition times.

\begin{tabular}{ll}
\hline Ambient density $\left(\mathrm{kg} / \mathrm{m}^{3}\right)$ & Transition time $(\mu \mathrm{s}$ ASOI $)$ \\
\hline 22.6 & 132 \\
34.5 & 108 \\
\hline
\end{tabular}

As discussed in the introduction, adherence to the linear relationship during the pre-break-up period is clearly a physical impossibility. In the very instance of needle opening the fuel will be accelerating from $0 \mathrm{~ms}^{-1}$ to an injection velocity observed here of approximately $70-100^{-1}$, the rate of change of penetration during this early period cannot be linear. The few data points available at this period make any extrapolation back to the origin susceptible to misinterpretation and should be avoided, as exemplified in the work [15].

Figs. 11-13 show the temporal evolution of the spray tip penetration for Diesel fuel at injection pressures of 500,700 and 1000 bar respectively, ambient density is $\rho_{a}=22.6 \mathrm{~kg} / \mathrm{m}^{3}$ and compares them to the models and data fits discussed in the introduction.

It is evident that the Hiroyasu model overestimates in all cases compared to the measured $S_{S}$, with an earlier transition time. At the lower injection pressure, the Kostas fit underestimates but as injection pressure increases it overestimates the tip penetration. A similar trend is observed with the Taskiran fit which uses a modified Hiroyasu model for the period after beak-up. It is this portion of the model which most closely matches the measured $S_{S}$ in the later stages of the injection. It is interesting that this modified Hiroyasu used by Taskiran is the first time that the nozzle geometry, in terms of conicity, is taken into account. Even with this, the measured data is a long way from that predicted in the various models, however, the difference between the models themselves shows the variability that is present in the literature concerning the temporal evolution of spray tip, both experimentally collected and modeled/data fitted.

The results presented pertaining to the spray cone angle and tip penetration of the emulsions has not been identified in previous emulsion spray works where these conditions and parameters have not been considered. The non-reactive, cold conditions of the ambient environment and the range of injection pressures used have no comparison in the literature [30-32].

\subsection{Summary and conclusion}

Sequences of consecutive images of Diesel fuel, D10 and D20 injection sprays were collected using a shadowgraph system at a frame rate of $30,075 \mathrm{fps}$. A research LED system was designed and built to provide illumination as an alternative to a laser system. Image sequences were used to determine the temporal evolution of the spray cone angle and the spray tip penetration for the fuel sprays. Three injection pressures, 500, 700 and 1000 bar were considered. Injections took place into nitrogen at an ambient tem-

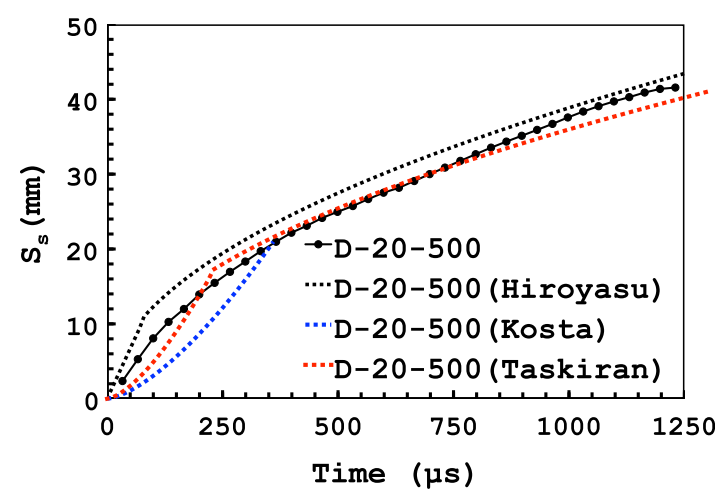

Fig. 11. Fuel injection spray tip penetration variation with time after SOI for Diese fuel. $P_{i n j}=500 . \rho_{a}=22.6 \mathrm{~kg} / \mathrm{m}^{3}$. Experimental in black, Hiyoyasu model (broken black), Kosta model (blue) and Taskiran model (red) for same condition. (For interpretation of the references to color in this figure legend, the reader is referred to the web version of this article.) 


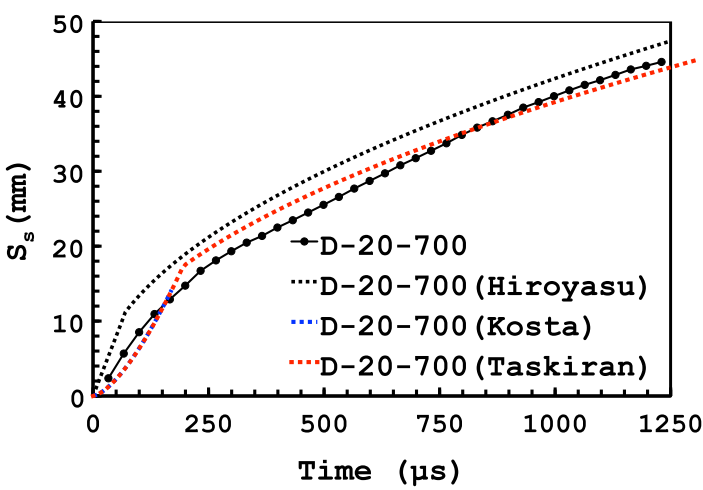

Fig. 12. Fuel injection spray tip penetration variation with time after SOI for Diesel fuel. $P_{i n j}=700 . \rho_{a}=22.6 \mathrm{~kg} / \mathrm{m}^{3}$. Experimental in black, Hiyoyasu model (broken black), Kosta model (blue) and Taskiran model (red) for same condition. (For interpretation of the references to color in this figure legend, the reader is referred to the web version of this article.)

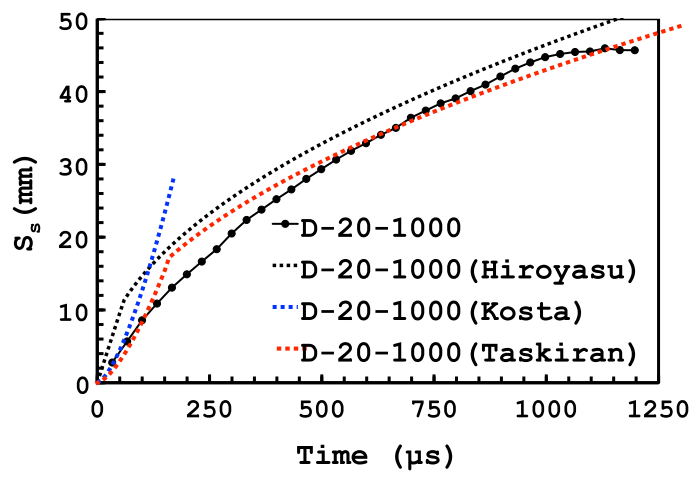

Fig. 13. Fuel injection spray tip penetration variation with time after SOI for Diese fuel. $P_{i n j}=1000 . \rho_{a}=22.6 \mathrm{~kg} / \mathrm{m}^{3}$. Experimental in black, Hiyoyasu model (broken black), Kosta model (blue) and Taskiran model (red) for same condition. (For interpretation of the references to color in this figure legend, the reader is referred to the web version of this article.)

perature of $20^{\circ} \mathrm{C}$ with two ambient densities of $22.6 \mathrm{~kg} / \mathrm{m}^{3}$ and $34.5 \mathrm{~kg} / \mathrm{m}^{3}$ (20 and 30 bar ambient pressure respectively). For each injection condition, a total of 15 injections was used to determine the mean spray angle and tip penetration. The following are primary observations made during the study:

- For all conditions the measured angle started at between $36^{\circ}$ and $52^{\circ}$. As the injections progressed, the angle gradually decreased until around $1000 \mu$ s after the SOI when the angle appeared to approach a quasi-steady value of between $18^{\circ}$ and $24^{\circ}$ for all conditions.

- The standard deviation of the mean spray angle, from the 15 injections used, reduced in value as the injections progressed, suggesting the spray formed a more stable less transient angle as injection progressed.

- The final five measurements were used to extract representative values of the spray angle for each condition for comparison purposes.

- The injection pressure had no discernible influence on the spray angle for the Diesel fuel sprays. For the D10 and D20 fuels, the spray angles for the 500 bar injections were considerably smaller than the spray angles for the 700 and 1000 bar injections.

- Increasing the ambient density resulted in a larger spray angle for the Diesel fuel sprays. For the D10 and D20 sprays, the increase in ambient density resulted in an increase in the spray angle for the 500 bar injections but not for the 700 and 1000 bar injections.
- With an injection pressure of 500 bar, both emulsions had a smaller spray angle than Diesel fuel at the same conditions.

From the results, the following conclusions were reached:

- Emulsification of the fuel lead to a reduction in the spray angle when the injection pressure was 500 bar.

- Emulsification of the fuel reduced the influence of the ambient gas density upon the spray angle when the injection pressure was 700 and 1000 bar.

- Measurements made at this temporal resolution support the previous models suggesting a linear dependence with time during the initial period, $S \propto t$ with a transition time after the SOI when the dependence changes to $S \propto t^{0.5}$.

- Previous models either under or overestimate tip penetration when compared with the measurements made in this work.

- The LED system used offers a cheap, reliable alternative illumination source for high speed imaging work.

\section{Acknowledgment}

The Authors would like to thank The EEA's Norway Grants for financial support through the RangEx project.

\section{References}

[1] Mohan B, Yang W, Chou S. Fuel injection strategies for performance improvement and emissions reduction in compression ignition engines: a review. Renew Sustain Energy Rev 2013;28(0):664-76.

[2] Namasivayam AM, Korakianitis T, Crookes RJ, Bob-Manuel KDH, Olsen J. Biodiesel, emulsified biodiesel and dimethyl ether as pilot fuels for natural gas fuelled engines. Appl Energy 2010;87(3):769-78.

[3] Fahd M, Wenming Y, Lee PS, Chou SK, Yap C. Experimental investigation of the performance and emission characteristics of direct injection diesel engine by water emulsion diesel under varying engine load condition. Appl Energy 2013;102(0):1042-9.

[4] Lin C, Chen L. Comparison of fuel properties and emission characteristics of two- and three-phase emulsions prepared by ultrasonically vibrating and mechanically homogenizing emulsification methods. Fuel 2008;87(1011):2154-61.

[5] Maiboom A, Tauzia X. NOx and PM emissions reduction on an automotive HSDI diesel engine with water-in-diesel emulsion and EGR: an experimental study. Fuel 2011;90(11):3179-92.

[6] Nadeem M, Rangkuti C, Anuar K, Haq MRU, Tan IB, Shah SS. Diesel engine performance and emission evaluation using emulsified fuels stabilized by conventional and gemini surfactants. Fuel 2006;85(14:15):2111-9.

[7] Liu H, Lee C, Huo Ming, Yao M. Comparison of ethanol and butanol as additives in soybean biodiesel using a constant volume combustion chamber. Energy Fuels 2011;25(4):1837-46.

[8] Armas O, Ballesteros R, Martos FJ, Agudelo JR. Characterization of light duty diesel engine pollutant emissions using water-emulsified fuel. Fuel 2005;84 (7-8):1011-8.

[9] Park JW, Huh KY, Park KH. Experimental study on the combustion characteristics of emulsified diesel in a rapid compression and expansion machine. Proc Inst Mech Eng Part D: J Automob Eng 2000;214(5):579-86.

[10] Qi D, Chen H, Matthews RD, Bian YZH. Combustion and emission characteristics of ethanol and biodiesel and water micro-emulsions used in a direct injection compression ignition engine. Fuel 2010;89(5):958-64.

[11] Abu-Zaid M. Performance of single cylinder, direct injection diesel engine using water fuel emulsions. Energy Convers Manage 2004;45(5):697-705.

[12] Lif A, Holmberg K. Water-in-diesel emulsions and related systems. Adv Colloid Interface Sci 2006:123:231-9.

[13] Roisman IV, Araneo L, Tropea C. Effect of ambient pressure on penetration of a diesel spray. Int J Multiph Flow 2007;33(8):904-20.

[14] Desantes J, Pastor J, Garca Oliver J, Pastor J. A 1D model for the description of mixing-controlled reacting diesel sprays. Combust Flame 2009;156 (1):234-49.

[15] Klein-Douwel R, Frijters P, Somers L, de Boer W, Baert R. Macroscopic diesel fuel spray shadowgraphy using high speed digital imaging in a high pressure cell. Fuel 2007:86(1213):1994-2007.

[16] Taskiran O, Ergeneman M. Experimental study on diesel spray characteristics and autoignition process. J Combust 2011:2011:20.

[17] Payri R, Salvador FJ, Gimeno J, Novella R. Flow regime effects on non-cavitating injection nozzles over spray behavior. Int J Heat Fluid Flow 2011;32 (1):273-84. 
[18] Dernotte J, Foucher F, Hespel C, Houill S. Experimental study of the effect of fuel properties on the diesel injection process. In: Proceedings of the European combustion meeting 2011; 2011.

[19] Ramos JI. Internal combustion engine modeling. Hemisphere; 1989.

[20] Hiroyasu H, Arai M. Structures of fuel sprays in diesel engines. SAE technical paper, $900475 ; 1990$.

[21] Naber J, Siebers D. Effects of gas density and vaporization on penetration and dispersion of diesel sprays. SAE technical paper, 960034; 1996.

[22] Delacourt E, Desmet B, Besson B. Characterisation of very high pressure diesel sprays using digital imaging techniques. Fuel 2005;84(7-8):859-67.

[23] Wang T, Han J, Xie X-B, Lai M, Henein N, Schwarz E, et al. Parametric characterization of high-pressure diesel fuel injection systems. J Eng Gas Turb Power 2003;125(2):412-26.

[24] Ghurri A, Jae-duk K, Kyu-Keun S, Jae-Youn J, Gon K. Qualitative and quantitative analysis of spray characteristics of diesel and biodiesel blend on common-rail injection system. J Mech Sci Technol 2011:25(4):885-93.

[25] Bougie B, Tulej M, Dreier T, Dam N, Ter Meulen J, Gerber T. Optical diagnostics of diesel spray injections and combustion in a high-pressure high-temperature cell. Appl Phys B 2005;80(8):1039-45.

[26] Shao J, Yan Y, Greeves G, Smith S. Quantitative characterization of diesel sprays using digital imaging techniques. Meas Sci Technol 2003;14(7):1110.

[27] Shao J, Yan Y. Digital imaging based measurement of diesel spray characteristics. In: Instrumentation and measurement technology conference, 2006. IMTC 2006. Proceedings of the IEEE; April 2006. p. 8-11.

[28] Eagle W, Morris S, Wooldridge M. High-speed imaging of transient diesel spray behavior during high pressure injection of a multi-hole fuel injector. Fuel 2014;116(0):299-309.

[29] Kostas J, Honnery D, Soria J. Time resolved measurements of the initial stages of fuel spray penetration. Fuel 2009;88(11):2225-37.

[30] Ochoterena R, Lif A, Nydn M, Andersson S, Denbratt I. Optical studies of spray development and combustion of water-in-diesel emulsion and microemulsion fuels. Fuel 2010;89(1):122-32.

[31] Huo M, Lin S, Nithyanandan $\mathrm{K}$, Liu $\mathrm{H}$, Lee $\mathrm{C}$. Effects of injection pressure and ambient temperature on spray characteristics of water emulsified diesel. In: ILASS Americas, 24th annual conference on liquid atomization and spray systems; 2012.

[32] Huo Ming, Lin Shenlun, Liu Haifeng, Chia-fon F Lee. Study on the spray and combustion characteristics of water emulsified diesel. Fuel 2014;123 (1):218-29.

[33] Wilson S, Gustafson G, Lincoln D, Murari K, Johansen C. Performance evaluation of an overdriven led for high-speed schlieren imaging. J Visual 2014:1-11.

[34] Buchmann N, Willert C, Soria J. Pulsed, high-power led illumination for tomographic particle image velocimetry. Exp Fluids 2012;53(5):1545-60.

[35] Willert C, Moessner S, Klinner J. Pulsed operation of high power light emitting diodes for flow velocimetry. In: 8TH international symposium on particle image velocimetry; 2009
[36] Willert C, Mitchell D, Soria J. Megahertz schlieren imaging of shock structure and sound waves in under-expanded, impinging jets. In: Gallery of fluid motion, 63rd annual APS-DFD meeting; 2010. Available from: 1010.3186

[37] Willert C, Stasicki B, Klinner J, Moessner S. Pulsed operation of high-power light emitting diodes for imaging flow velocimetry. Meas Sci Technol 2010;21 (7):075402.

[38] Willert C, Mitchell D, Soria J. An assessment of high-power light-emitting diodes for high frame rate schlieren imaging. Exp Fluids 2012:53(2):413-21.

[39] Luminus Devices Inc. Technical product data sheet CNBT-40 product range, pds-001229rev03 edition; 2011.

[40] Lin Y, Lin H. Spray characteristics of emulsified castor biodiesel on engine emissions and deposit formation. Renew Energy 2011;36(12):3507-16.

[41] Zhang D, Lin Y, Li A, Tarasov VV. Emulsification for castor biomass oil. Front Chem Sci Eng 2011;5(1):96-101.

42] Emberson DR, Ihracska B, Imran S, Diez A, Lancaster M, Korakianitis T. Hydraulic characterization of Diesel and water emulsions using momentum flux. Fuel 2015;162(0):23-33.

[43] Attia A, Kulchitskiy A. Influence of the structure of water-in-fuel emulsion on diesel engine performance. Fuel 2014;116(0):703-8.

[44] Bulent Koc A, Abdullah M. Performance and NOx emissions of a diesel engine fueled with biodiesel-diesel-water nanoemulsions. Fuel Process Technol 2013;109(0):70-7.

[45] Cucheval A, Chow RCY. A study on the emulsification of oil by power ultrasound. Ultrason Sonochem 2008;15(5):916-20.

[46] Lin C, Chen L. Emulsification characteristics of three- and two-phase emulsions prepared by the ultrasonic emulsification method. Fuel Process Technol 2006;87(4):309-17.

[47] Emberson D. Diesel fuel and Diesel fuel with water emulsions spray and combustion characterization. PhD thesis. QMUL; 2015.

[48] Morgan R, Wray J, Kennaird DA, Crua C, Heikal MR. The influence of injector parameters on the formation and break-up of a diesel spray. SAE technical paper, 2001-01-0529; 2001.

[49] Kang J, Bae C, Lee KO. Initial development of non-evaporating diesel sprays in common-rail injection systems. Int J Engine Res 2003;4(4):283-98.

[50] Wang X, Huang Z, Kuti O, Zhang Wu, Nishida K. Experimental and analytical study on biodiesel and diesel spray characteristics under ultra-high injection pressure. Int J Heat Fluid Flow 2010;31(4):659-66.

[51] Payri R, Garca A, Domenech V, Durrett R, Plazas A. An experimental study of gasoline effects on injection rate, momentum flux and spray characteristics using a common rail diesel injection system. Fuel 2012;97(0):390-9.

[52] Payri D, Arregle J. Characterization of d.i. diesel sprays in high density conditions. SAE technical paper, 960774; 1996.

[53] Payri R, Salvador F, Gimeno J, Soare V. Determination of diesel sprays characteristics in real engine in-cylinder air density and pressure conditions. J Mech Sci Technol 2005;19(11):2040-52. 